\title{
Physical activity improves sleep quality in women
}

\author{
Magdalena Dabrowska-Galas ${ }^{1}$, Jolanta Dabrowska² \\ ${ }^{1}$ Department of Kinesitherapy and Special Methods, School of Health Sciences in Katowice, \\ Medical University of Silesia, Katowice, Poland \\ ${ }^{2}$ Department of Sports Medicine and Physiology of Physical Effort, School of Health Sciences in Katowice, \\ Medical University of Silesia, Katowice, Poland
}

\begin{abstract}
Objectives: The aim of the study was to check whether women with a higher level of physical activity are less likely to experience sleep problems.

Material and methods: 80 women aged 45-65 from Silesia took part in the pilot study.

The research tool was a self-survey, the International Physical Activity Questionnaire (IPAQ), the Athens Insomnia Scale (AIS), and the Menopause Rating Scale (MRS). The data was prepared in the STATISTICA 10 program.

Results: The mean age of the respondents was $51.75 \pm 5.57$. The most common symptoms were psychological problems (mean MRS: $4.29 \pm 3.25$ ).

A sedentary lifestyle was reported in $57.14 \%$ of the respondents. There was a significant difference between women suffering from insomnia and women with normal sleep in terms of the level of physical activity $(p=0.025)$.

Conclusions: Physical activity significantly affects the quality of sleep among middle-aged women.

Key words: IPAQ; MRS, AIS; menopause
\end{abstract}

Ginekologia Polska 2021; 92, 7: 487-490

\section{INTRODUCTION}

Physical activity (PA) is defined as any form of body movement caused by muscle contractions, where energy expenditure exceeds resting energy levels and physical fitness is improved [1]. Regular physical activity has many health benefits, so it is very important to do regular exercises every day. Nevertheless, despite the well-known benefits of regular exercise, most middle-aged women are not physically active enough $[2,3]$. What is more, the results of the research show that the decline in physical activity begins in middle-aged women (45-65 years old) [2, 4]. According to the guidelines of the World Health Organization (WHO), adults should engage in at least 150 minutes of moderate physical intensity (3-6 METs, where the metabolic equivalent of $1 \mathrm{MET}$ is defined as the amount of oxygen consumed while sitting at rest and is $3.5 \mathrm{~mL} \mathrm{O} 2$ per kg. body weight/min) per week, or at least 75 minutes of intense intensity (6 METs) per week, or a combination of moderate and high intensity PA. Moreover, all adults should perform moderate to vigorous strength exercise two or more days a week that covers all major muscle groups. The guidelines also encourage adults to avoid a sedentary lifestyle, as any, even the smallest dose of physical activity is better than total lack of PA [5]. The results of the most recent studies show that approximately $27 \%$ of middle-aged women meet the guidelines for physical activity $[6,7]$. Middle-aged women may experience many mental and somatic disorders that reduce their quality of life. Sleep problems are very common among menopausal women $[8,9]$. The results of studies on 12,603 menopausal women showed that $38 \%$ of respondents had sleep problems [10]. The results of another study, carried out on a group of 6,079 menopausal women showed that $43 \%$ suffered from insomnia [11].

Sleep problems in menopausal women are associated with numerous factors including age-related physiological changes, menopausal symptoms, stress, mood disorders, and chronic health problems [12]. Although sleep problems are common in middle-aged women, there is a lack of research into the prevalence of this problem related to women's levels of physical activity.

The aim of the research was to verify, whether women with higher levels of physical activity are less likely to experience sleep problems.

\section{Corresponding author:}

Magdalena Dabrowska-Galas

Department of Kinesitherapy and Special Methods, School of Health Sciences in Katowice, Medical University of Silesia, Katowice, 12 Medykow St, 40-752 Katowice, Poland e-mail: mdabrowska-galas@sum.edu.pl 


\section{MATERIAL AND METHODS}

80 women aged 45-65 from Silesia took part in the pilot studies. Participation in the study was voluntary and anonymous. The inclusion criteria for the research were: age 45-65 years, consent to participate in the research. The exclusion criteria were depression in the history, contraindications to physical activity, incomplete completed questionnaire. 17 people were excluded from the analysis. The study protocol was reviewed and approved by the Bioethical Committee of the Medical University of Silesia in Katowice (KNW/0022/KB/103/18).

\section{The Athenian Insomnia Scale (AIS)}

The Athenian Insomnia Scale (AIS) was used to assess insomnia, which is one of the most commonly used scales both for diagnostic purposes and in research into the effectiveness of treating insomnia [13]. The AIS is a short, eight-point scale that measures the symptoms of insomnia [14]. The validation studies showed high reliability and validity of this tool [15]. A score on the AIS scale of 6 or more points means a value that allows to conclude the occurrence of insomnia (scale sensitivity - 93\%, scale specificity - 85\%) [14].

\section{The International Physical Activity Questionnaire (IPAQ)}

The International Physical Activity Questionnaire (IPAQ) was used to assess the level of physical activity - short form (IPAQ-SF). The International Physical Activity Questionnaire-Short Form (IPAQ-SF) is a self-report questionnaire evaluating the physical activity level among adults ranging from 15 to 69 years. The questionnaire consists of questions about the frequency and duration of low, moderate and high intensity physical activity for at least 10 minutes continuously in the last 7 days $[16,17]$. Physical activity level was expressed as MET-min (where the metabolic equivalent of 1 MET is defined as the amount of oxygen consumed when sitting at rest and is $3.5 \mathrm{~mL} \mathrm{O} 2$ per $\mathrm{kg}$ body weight $/ \mathrm{min}$ ) per week and calculated by multiplying the MET assigned to it (vigorous - $8 \mathrm{MET}$, moderate - 4MET and walking - 3.3 MET), by the number of days it was performed during the previous 7 days. According to the IPAQ guidelines, women were classified to group with low, moderate or high levels of physical activity.

\section{Menopause Rating Scale (MRS)}

The validated and standardized MRS scale was used to assess the severity of menopausal symptoms. MRS contains 11 descriptions of climacteric symptoms, including: hot flashes, sweating, heart problems, sleep problems, depressed mood, irritability, anxiety, physical and mental exhaustion, sexual problems, bladder problems, vaginal dryness, discomfort associated with joints and muscles.
The intensity of each symptom is rated on a scale of 0 (no symptoms) to 4 (very severe). The symptoms are presented in 3 groups:

1. psychological symptoms described in questions 4 to 7 ,

2. somatic and vegetative symptoms - questions 1,2 , 3 and 11 ,

3. urogenital symptoms - questions 8,9 and 10 .

The total sum of points obtained on the MRS scale ranged from 0 , which meant no menopausal symptoms, to 44 , which was characterized by the highest intensity of symptoms [18, 19].

Statistical analysis was performed using the Statistica 10 (Statistica v10, StatSoft, Krakow, Poland). Arithmetic means, median, standard deviations, and range of variability (extreme values) were calculated for measurable variables. Frequency of occurrence (percent) was calculated for qualitative variables. All quantitative type variables were checked by Shapiro-Wilk test to determine the type of distribution. The chi-square test was used to perform the relationship between IPAQ and AIS value. The level of $a=0.05$ was used for all comparisons.

\section{RESULTS}

The mean age of the respondents was $51.75 \pm 5.57$. Women declared menopausal symptoms, with the least degree of urogenital problems (mean $2.3 \pm 2.5$ ) and the highest degree of psychological symptoms $(4.29 \pm 3.25)$. Most of respondents had higher education (69.84\%), lived in the city (79.37\%), led a sedentary lifestyle (57.14\%). The problem of insomnia concerned $44.44 \%$ of women (Tab. 1 ).

The results showed that there was a difference between women suffering from insomnia and women with proper sleep in terms of the level of physical activity $(p=0.025)$. The greatest problem of insomnia concerned physically inactive women (64.29\%). Women with high physical activity did not declare insomnia problem (Tab. 2).

\section{DISCUSSION}

Middle-aged women experience a wide range of symptoms associated with this period of life. The results of many studies showed that women most often complained of urogenital and somatic symptoms [7, 20-23]. The results of our study showed that women most often declared the occurrence of psychological and somatic symptoms, which is confirmed by the results of other studies conducted on a group of women during perimenopause $[24,25]$. Low level of physical activity affects more than half of middle-aged women, which is confirmed by the results of our study [26]. In middle-aged women there is a decline in physical activity $[2,4,27]$. Many authors have proven the effect of physical activity on the alleviation of menopausal symptoms [7, 26, 28]. Although many studies concern the issue of physical activity 


\begin{tabular}{|c|c|c|c|c|c|}
\hline & Mean & Median & Min & $\operatorname{Max}$ & SD \\
\hline Age & 51.75 & 52.00 & 45.00 & 65.00 & 5.57 \\
\hline BMI & 24.53 & 24.13 & 17.69 & 35.76 & 2.87 \\
\hline MRS psychological symptoms & 4.29 & 4.00 & 0.00 & 12.00 & 3.25 \\
\hline MRS somatic symptoms & 3.71 & 3.00 & 0.00 & 12.00 & 2.85 \\
\hline MRS urogenital symptoms & 2.30 & 2.00 & 0.00 & 10.00 & 2.50 \\
\hline Variable & $\mathbf{N}$ & $\%$ & & & \\
\hline \multicolumn{6}{|l|}{ Educational level } \\
\hline $\begin{array}{l}\text { University } \\
\text { High school } \\
\text { Elementary school }\end{array}$ & $\begin{array}{c}44 \\
8 \\
11\end{array}$ & $\begin{array}{l}69.84 \\
12.70 \\
17.46\end{array}$ & & & \\
\hline \multicolumn{6}{|l|}{ Place of living } \\
\hline $\begin{array}{l}\text { Country } \\
\text { Village }\end{array}$ & $\begin{array}{l}50 \\
13\end{array}$ & $\begin{array}{l}79.37 \\
20.63\end{array}$ & & & \\
\hline \multicolumn{6}{|l|}{ A permanent partner } \\
\hline $\begin{array}{l}\text { Yes } \\
\text { No }\end{array}$ & $\begin{array}{c}56 \\
7\end{array}$ & $\begin{array}{l}88.89 \\
11.11\end{array}$ & & & \\
\hline \multicolumn{6}{|l|}{ PA level (IPAQ) } \\
\hline $\begin{array}{l}\text { Low } \\
\text { Moderate } \\
\text { High }\end{array}$ & $\begin{array}{c}36 \\
19 \\
8\end{array}$ & $\begin{array}{l}57.14 \\
30.16 \\
12.70\end{array}$ & & & \\
\hline \multicolumn{6}{|l|}{ Insomnia } \\
\hline $\begin{array}{l}\text { Yes } \\
\text { No }\end{array}$ & $\begin{array}{l}28 \\
35\end{array}$ & $\begin{array}{l}44.44 \\
55.56\end{array}$ & & & \\
\hline \multicolumn{6}{|l|}{ Insomnia } \\
\hline $\begin{array}{l}\text { Yes } \\
\text { No }\end{array}$ & $\begin{array}{l}28 \\
35\end{array}$ & $\begin{array}{l}44.44 \\
55.56\end{array}$ & & & \\
\hline
\end{tabular}

$\mathrm{BMI}$ - body mass index; SD — standard deviation; MRS — menopause rating scale; IPAQ — International Physical Activity Questionnaire

Table 2. The level of physical activity and insomnia

\begin{tabular}{|l|c|c|c|c|}
\hline \multirow{2}{*}{$\begin{array}{l}\text { Insomnia } \\
\text { (AIS) }\end{array}$} & \multicolumn{4}{|c|}{ Physical activity level (IPAQ) } \\
\cline { 1 - 4 } & Low & Moderate & High & p \\
\hline Yes & $64.29 \%$ & $35.71 \%$ & $0.00 \%$ & \\
\hline No & $51.43 \%$ & $25.71 \%$ & $22.86 \%$ & $\mathrm{p}=0.025$ \\
\hline
\end{tabular}

IPAQ - International Physical Activity Questionnaire; AIS — Athens Insomnia Scale

in perimenopausal women and its impact on menopausal symptoms, there are no reports on the relationship between $\mathrm{AF}$ in the context of sleep quality in this group of women. The fact, that sleep worsens during the menopause is widespread among women and clinicians [29-32]. The results of our study showed that insomnia affected a significant part of middle-aged women (64.29\%). This is confirmed by the fact that this problem affects a significant percentage of middle-aged women around the world, as about $44 \%$ of Spanish women, $41 \%$ of respondents from Ecuador, $51 \%$ of Japanese women, and $54 \%$ of respondents from Turkey suffer from insomnia [11, 33-35].The above data from different regions of the world seem to be consistent and emphasize the fact that about half of middle-aged women experience sleep problems.

The aim of this study was to assess the relationship between the level of physical activity and insomnia in middle-aged women. The results showed that women with a high level of physical activity did not complain about the problem of insomnia at all, while women with a sedentary lifestyle were much more likely to suffer from insomnia. The lack of reports in the literature makes it impossible to compare this issue with the results of other authors, therefore the research will be continued on a larger population of women.

\section{CONCLUSIONS}

Physical activity significantly affects the sleep quality of middle-aged women.

The health benefits of physical activity are well known. However, there is a need to educate women in this area to present this non-pharmacological method of sleep improvement. The research will be continued on a larger group, taking into account other factors that may correlate with sleep. 


\section{Funding}

This project was supported by a Medical University of Silesia in Katowice (Contract KNW-2-Z26/N/8/N).

\section{Conflict of interest}

The authors declare no conflict of interest.

\section{REFERENCES}

1. Daley A, MacArthur C, McManus R, et al. Factors associated with the use of complementary medicine and non-pharmacological interventions in symptomatic menopausal women. Climacteric. 2006; 9(5): 336-346, doi: 10.1080/13697130600864074, indexed in Pubmed: 17000582.

2. U.S. Department of Health and Human Services. 2008 Physical Activity Guidelines for Americans. www.health.gov/paguidelines (18.06.2020).

3. Pettee Gabriel KK, Morrow JR, Woolsey ALT. Framework for physical activity as a complex and multidimensional behavior. J Phys Act Health. 2012; 9 Suppl 1: S11-S18, doi: 10.1123/jpah.9.s1.s11, indexed in Pubmed: 22287443.

4. Dąbrowska J, Dąbrowska-Galas M, Naworska B, et al. The role of physical activity in preventing obesity in midlife women. Prz Menopauzalny. 2015; 14(1): 13-19, doi: 10.5114/pm.2015.49252, indexed in Pubmed: 26327883.

5. World Health Organization (Europe). Physical Activity. http://www.euro. who.int/en/health-topics/disease-prevention/physical-activity/physical-activity (18.06.2020)

6. CDC National Health and Nutrition Examination Survey. http://www.cdc. gov/nchs/nhanes/nhanes_questionnaires.htmL (18.06.2020).

7. Dąbrowska-Galas M, Dąbrowska J, Ptaszkowski K, et al. High Physical Activity Level May Reduce Menopausal Symptoms. Medicina (Kaunas). 2019; 55(8), doi: 10.3390/medicina55080466, indexed in Pubmed: 31405242.

8. Gozuyesil E, Gokyildiz Surucu S, Alan S. Sexual function and quality-of-life-related problems during the menopausal period. J Health Psychol. 2018; 23(14): 1769-1780, doi: 10.1177/1359105317742194, indexed in Pubmed: 29243521

9. Morin $C M$, LeBlanc $M$, Bélanger $L$, et al. Prevalence of insomnia and its treatment in Canada. Can J Psychiatry. 2011; 56(9): 540-548, doi: 10.1177/070674371105600905, indexed in Pubmed: 21959029.

10. Kravitz HM, Ganz PA, Bromberger J, et al. Sleep difficulty in women at midlife: a community survey of sleep and the menopausal transition. Menopause. 2003; 10(1): 19-28, doi: 10.1097/00042192-20031001000005, indexed in Pubmed: 12544673.

11. Blümel JE, Cano A, Mezones-Holguín $E$, et al. A multinational study of sleep disorders during female mid-life. Maturitas. 2012; 72(4): 359-366, doi: 10.1016/j.maturitas.2012.05.011, indexed in Pubmed: 22717489.

12. Monteleone P, Mascagni G, Giannini A, et al. Symptoms of menopause - global prevalence, physiology and implications. Nat Rev Endocrinol. 2018; 14(4): 199-215, doi: 10.1038/nrendo.2017.180, indexed in Pubmed: 29393299.

13. Buysse DJ, Ancoli-Israel S, Edinger JD, et al. Recommendations for a standard research assessment of insomnia. Sleep. 2006; 29(9): 1155-1173, doi: 10.1093/sleep/29.9.1155, indexed in Pubmed: 17040003.

14. Soldatos CR, Dikeos DG, Paparrigopoulos TJ. Athens Insomnia Scale: validation of an instrument based on ICD-10 criteria. J Psychosom Res. 2000; 48(6): 555-560, doi: 10.1016/s0022-3999(00)00095-7, indexed in Pubmed: 11033374.

15. Fornal-Pawłowska M, Wołyńczyk-Gmaj D, Szelenerger W. Walidacja Ateńskiej Skali Bezsenności. Psychiatria Polska. 2011; 45(2): 211-221.

16. International Physical Activity Questionnaire. http://www.ipaq.ki.se (18.06.2020).

17. Dąbrowska-Galas M, Plinta R, Dąbrowska J, et al. Physical activity in students of the Medical University of Silesia in Poland. Phys Ther. 2013; 93(3): 384-392, doi: 10.2522/ptj.20120065, indexed in Pubmed: 23086407.
18. Heinemann LAJ, Potthoff $P$, Schneider HPG. International versions of the Menopause Rating Scale (MRS). Health Qual Life Outcomes. 2003; 1:28, doi: 10.1186/1477-7525-1-28, indexed in Pubmed: 12914663.

19. Thapa R, Yang Y. Menopausal symptoms and related factors among Cambodian women. Women \& Health. 2019; 60(4): 396-411, doi: 10.1080/03630242.2019.1643815.

20. Gold EB, Crawford SL, Avis NE, et al. Factors related to age at natura menopause: longitudinal analyses from SWAN. Am J Epidemiol. 2013; 178(1): 70-83, doi: 10.1093/aje/kws421, indexed in Pubmed: 23788671.

21. Larroy C, Marin Martin C, Lopez-Picado A, et al. The impact of perimenopausal symptomatology, sociodemographic status and knowledge of menopause on women's quality of life. Arch Gynecol Obstet. 2020; 301(4): 1061-1068, doi: 10.1007/s00404-019-05238-1, indexed in Pubmed: 31302734

22. Dąbrowska-Galas M, Dąbrowska J, Michalski B. Sexual Dysfunction in Menopausal Women. Sexual Medicine. 2019; 7(4): 472-479, doi: 10.1016/j.esxm.2019.06.010.

23. Nazarpour S, Simbar M, Tehrani F, et al. The relationship between menopausal symptoms and sexual function. Women \& Health. 2018; 58(10): 1112-1123, doi: 10.1080/03630242.2017.1414100.

24. Rahman SA, Zainudin SR, Mun VL. Assessment of menopausal symptoms using modified Menopause Rating Scale (MRS) among middle age women in Kuching, Sarawak, Malaysia. Asia Pac Fam Med. 2010; 9(1): 5 , doi: 10.1186/1447-056X-9-5, indexed in Pubmed: 20175928.

25. Chuni N, Sreeramareddy CT. Frequency of symptoms, determinants of severe symptoms, validity of and cut-off score for Menopause Rating Scale (MRS) as a screening tool: a cross-sectional survey among midlife Nepalese women. BMC Womens Health. 2011; 11:30, doi: 10.1186/14726874-11-30, indexed in Pubmed: 21672198.

26. Kim MJ, Cho J, Ahn Y, et al. Association between physical activity and menopausal symptoms in perimenopausal women. BMC Womens Health. 2014; 14: 122, doi: 10.1186/1472-6874-14-122, indexed in Pubmed: 25277534.

27. Bondarev D, Laakkonen EK, Finni T, et al. Physical performance in relation to menopause status and physical activity. Menopause. 2018; 25(12): 1432-1441, doi: 10.1097/GME.0000000000001137, indexed in Pubmed: 29787482.

28. McAndrew LM, Napolitano MA, Albrecht A, et al. When, why and for whom there is a relationship between physical activity and menopause symptoms. Maturitas. 2009; 64(2): 119-125, doi: 10.1016/j.maturitas.2009.08.009, indexed in Pubmed: 19781877.

29. Kalleinen N, Polo-Kantola P, Himanen SL, et al. Sleep and the menopause - do postmenopausal women experience worse sleep than premenopausal women? Menopause Int. 2008; 14(3): 97-104, doi: 10.1258/mi.2008.008013, indexed in Pubmed: 18714074.

30. Shin C, Lee $S$, Lee $T$, et al. Prevalence of insomnia and its relationship to menopausal status in middle-aged Korean women. Psychiatry Clin Neurosci. 2005; 59(4): 395-402, doi: 10.1111/j.1440-1819.2005.01391.x, indexed in Pubmed: 16048444.

31. Xu M, Bélanger $L$, Ivers $H$, et al. Comparison of subjective and objective sleep quality in menopausal and non-menopausal women with insomnia. Sleep Med. 2011; 12(1): 65-69, doi: 10.1016/j.sleep.2010.09.003, indexed in Pubmed: 21147026.

32. Perger $E$, Mattaliano $P$, Lombardi C. Menopause and Sleep Apnea. Maturitas. 2019; 124:35-38, doi: 10.1016/j.maturitas.2019.02.011, indexed in Pubmed: 31097176

33. Arakane $M$, Castillo $C$, Rosero MF, et al. Factors relating to insomnia during the menopausal transition as evaluated by the Insomnia Severity Index. Maturitas. 2011; 69(2): 157-161, doi: 10.1016/j.maturitas.2011.02.015, indexed in Pubmed: 21444163.

34. Terauchi M, Obayashi S, Akiyoshi M, et al. Insomnia in Japanese periand postmenopausal women. Climacteric. 2010; 13(5): 479-486, doi: 10.3109/13697130903353478, indexed in Pubmed: 19886814

35. Timur S, Sahin NH. Effects of sleep disturbance on the quality of life of Turkish menopausal women: a population-based study. Maturitas. 2009; 64(3): 177-181, doi: 10.1016/j.maturitas.2009.08.016, indexed in Pubmed: 19815356 